\title{
Causal Foundationalism, Physical Causation, and Difference-Making
}

\author{
Luke Glynn \\ lglynn@caltech.edu \\ Published in Synthese, Vol. 190, No. 6 (April 2013), pp. 1017-1037. \\ DOI 10.1007/s11229-011-0058-7. \\ $<$ http://link.springer.com/article/10.1007\%2Fs11229-011-0058-7>. \\ Please cite published version only.
}

\section{Introduction}

An influential (indeed the currently dominant) tradition in the philosophy of token causation seeks to analyze that relation in terms of difference-making. ${ }^{1}$ Counterfactual, probabilistic, and (at least some) regularity theories belong to this tradition (cp. Strevens 2004, pp. 160-4), diverging from one another in the sort of difference-making to which they appeal. Counterfactual theories appeal to counterfactual difference-making. On the simplest such theory, an event $c$ is a cause of a distinct event $e$ just in case, if $c$ hadn't occurred, then $e$ wouldn't have occurred either. ${ }^{2}$ Probabilistic theories appeal to probabilistic difference-making. In the simplest case, $c$ is taken to be a cause of $e$ just in case $c$ makes a difference to the probability of $e$ : specifically, just in case the probability of $e$ given $c$ is higher than the probability of $e$ given the non-occurrence of c. ${ }^{3}$ Finally, regularity analyses typically appeal to nomic difference-making: according to Mackie's (1965) regularity theory, for $c$ to count as a cause of $e, c$ must (at least) be a nonredundant component of a set $S$ of antecedent conditions nomically sufficient for $e$. The nonredundancy of $c$ to $S$ ensures that $c$ makes a difference to $e$ (cp. Strevens 2004, p. 163): without $c, S$ wouldn't have sufficed for $e^{4}$ 
The difference-making approach has not gone unchallenged. Its principal rival is a tradition that instead seeks to analyze token causation in terms of process connections. ${ }^{5}$ The development of this latter tradition has, in part, been motivated by the perceived shortcomings of differencemaking theories (see Dowe 2000, Ch. 2). In particular, pre-emption cases of varying degrees of sophistication (see e.g. Lewis 1986b, Postscript E; Schaffer 2000a; and Hall and Paul 2003) pose difficulties for difference-making accounts (see Strevens 2007, p. 94). Pre-emption cases are those in which an event $c$ causes an event $e$, but there exists a backup $b$ that would have brought about $e$ even in the absence of $c$ (perhaps $b$ is even sufficient in the circumstances for $e$ ). So it is not true that, if $c$ hadn't occurred, then $e$ wouldn't have occurred (and perhaps it is true that $b$, though not a cause of $e$, was a non-redundant component of a set $T$ of antecedent conditions nomically sufficient for $e$ ). Probabilistic preemption cases can be described in which, though $b$ might not have brought about $e$ in the absence of $c, b$ nevertheless ensures that the probability of $e$ would have been the same in the absence of $c$ as in its presence. In such cases, $c$ doesn't make a probabilistic difference to $e$.

Advocates of the difference-making approach respond to the pre-emption problem by invoking subtle patterns of difference-making. A promising approach appeals to so-called de facto dependence (Yablo 2002, 2004). The idea is that causes make a difference to their effects when certain features of the actual situation are held fixed. On the counterfactual approach, for example, holding fixed means including the proposition that the relevant features obtain in the antecedent of the counterfactual (cp. Hitchcock 2001b, p. 374), yielding what Hitchcock (2001a, p. 275) calls an explicitly non-foretracking (ENF) counterfactual. Thus, if $c$ pre-empts $b$ (or $b_{1}$, $\ldots$, and $b_{n}$ ) as a cause of $e$ then, while the simple-antecedent counterfactual if $c$ hadn't occurred, then e wouldn't have occurred is false, the ENF if c hadn't occurred, and $b$ (alternatively, $b_{1}, \ldots$, 


\section{Luke Glynn}

and $b_{n}$ ) hadn't occurred either, then e wouldn't have occurred is true. Attempts have been made to define an analogous notion of de facto probabilistic dependence (see Hitchcock 2001b; and Glynn 2011; for a related approach, see Kvart 2004), while Baumgartner (ms.) argues that a regularity theory of causation can be developed that performs at least as well as analyses in terms of de facto counterfactual dependence. ${ }^{6}$

Difference-making theorists also point out that process accounts are themselves not without problems: notably, there is a problem of distinguishing causal processes from so-called pseudoprocesses and of distinguishing genuine causal interactions from (mere) space-time intersections (for discussion, see Salmon 1984, Chs. 5-6, 1994, 1997; Hitchcock 1995, 2009; Dowe 1992, 2000, Ch. 5; and Choi 2002). Arguably there is also a problem of accommodating cases of causation involving absences and omissions (see Dowe 2000, Ch. 6; Schaffer 2000b; and Hall 2004, pp. 243, 249). ${ }^{7}$

A second debate, initiated a century ago by Russell (1913), concerns whether, or to what extent, the causal claims of common sense and the special sciences have a basis in fundamental physical theory. This debate has undergone a recent revival (see Field 2003; and the papers collected in Price and Corry (2007); see also Suppes 1970, pp. 5-6). Woodward (2007, p. 70) has, rather aptly, dubbed the view that high-level causal claims do have a basis in fundamental physics 'causal foundationalism'. According to an extreme causal foundationalism,

"[...] fundamental physical laws supply a causal foundation for all of the causal claims occurring in the special sciences and [...] every application of a fundamental physical theory must be interpretable in terms of a notion of 'cause' possessing all of the features of the notion that figures in common sense and the special sciences." (Woodward 2007, p. 70) 
Extreme anti-foundationalists, such as Russell, maintain by contrast that the causal claims of common sense and the special sciences have no basis in physics. These two positions might be thought of as characterizing the two ends of a continuum, with more moderate positions arranged along its intermediate points. ${ }^{8}$

The first of the two debates - over whether the correct analysis of causation is a differencemaking or a process account (or something else entirely) - may bear substantially upon the second. If it turns out that physics seeks and discovers processes but not difference-making relations, or vice versa, then whether our ordinary concept of cause is to be analyzed in terms of processes or difference-making seems highly relevant to the question of whether there is a physical basis for our ordinary causal talk. ${ }^{9}$

While the relevance of the debate concerning difference-making and process theories to that over causal foundationalism is clear, it is less obvious that the latter debate should bear on the former. Yet, in an interesting recent paper, Ney (2009; all subsequent references to Ney are to this paper) advances an argument that purports to show just this. Specifically, Ney advances a rather direct argument for the truth of causal foundationalism, which in turn she takes to imply that causation is not fundamentally a matter of difference-making.

Ney's argument, if it goes through, is interestingly different from standard criticisms of difference-making theories of causation. Its main conclusion is not (like the usual arguments from the existence of pre-emption cases) that difference-making theories lack extensional adequacy. Its principal conclusion is not, in other words, that causation is not a matter of difference-making. Rather, it is that causation is not fundamentally a matter of differencemaking. ${ }^{10}$ Ney's objection is thus that, even if a difference-making analysis could be developed that correctly diagnosed all and only actual and possible cases of causation as such, nevertheless 


\section{Luke Glynn}

that analysis would not be sufficiently deep to be satisfactory. ${ }^{11}$ Metaphysically speaking, Ney's central point is that there are facts (process facts, as it turns out) that are causal and that are more basic than difference-making facts, in the sense that difference-making facts depend upon them.

It is this rather non-standard critique of the difference-making approach with which this paper is concerned. The plan is as follows. In $\S 2$, the basic structure of Ney's main argument is described. In $\S \S 3-4$ the argument is fleshed out, and it is argued that a central premise is not adequately supported. In $\S 5$, the difference-making approach is defended from two supplementary arguments offered by Ney. Then, in $\S 6$, it is argued that there is prima facie reason to think, pace Ney, that causation is fundamentally a matter of difference-making, and that therefore the difference-making approach is metaphysically deep after all. Finally, in (§7), some brief concluding remarks are offered about where all this leaves the debate over causal foundationalism.

\section{The Outline of Ney's Argument}

In her paper, Ney distinguishes two sorts of causal fact, which she respectively dubs "facts about difference-making" and "facts about physical causation" (p. 739). She argues that these different types of causal fact "bear an important relationship to each other" (ibid.). Specifically, Ney defends the thesis that "difference-making facts depend upon the facts of physical causation" (p. 740). Borrowing Woodward's terminology, she calls this thesis "foundationalism about causation" (ibid.), and takes it to imply that "causation is not fundamentally a matter of difference-making" (p. 758).

The first thing to note is the apparent discrepancy between causal foundationalism as characterized by Ney and by Woodward. On Woodward's characterization (quoted in $\S 1$ above) the thesis is (roughly speaking) that the causal claims of common sense and the special sciences 
are underwritten by fundamental physical theory. Unlike Ney's, Woodward's characterization makes no mention of difference-making facts. As characterized by Woodward, the term foundationalism is apt. But prima facie it is unclear why Ney's thesis deserves that name.

To see why it does, note that Ney thinks the causal claims of common sense and the special sciences $d o$ roughly track difference-making facts (p. 761). Ney's characterization of causal foundationalism thus (I suggest) straightforwardly derives from Woodward's by incorporating the assumption that ordinary and special scientific causal claims express difference-making facts. Ney takes difference-making facts to be dependent upon facts about physical causation (facts presumably discovered by physics), and takes this to imply that causation is not fundamentally a matter of difference-making.

In $\S \S 3-4$, Ney's argument will be fleshed out. But enough has already been said to allow a sketch of the line of response that I will pursue. The problem upon which I wish to focus is that Ney's causal foundationalist thesis, that

$\boldsymbol{C F}$ : difference-making facts depend upon the facts about physical causation,

does not obviously imply the conclusion she draws from it, namely,

C: $\quad$ causation is not fundamentally a matter of difference-making.

In fact, $(\boldsymbol{C F})$ implies $(\boldsymbol{C})$ only if the following proposition is analytic:

P: Difference-making facts are not among the facts about physical causation.

If $(\boldsymbol{P})$ is not analytic then, in order to get a valid argument from $(\boldsymbol{C F})$ to $(\boldsymbol{C}),(\boldsymbol{P})$ must be explicitly included as an additional premise. 


\section{Luke Glynn}

Whether or not $(\boldsymbol{P})$ is analytic depends crucially on the meaning of 'facts about physical causation'. Plausibly Ney does not construe 'facts about physical causation' in such a way as to make $(\boldsymbol{P})$ analytic. It shall be seen $(\S 3)$ that, if she did, then her arguments for $(\boldsymbol{C F})$ would not go through, and $(\boldsymbol{C F})$ would be unsupported. ${ }^{12}$

But if 'facts about physical causation' is understood (as Ney plausibly understands it) in such a way that $(\boldsymbol{P})$ is not analytic, then Ney is unjustified in taking $(\boldsymbol{P})$ to be true (or so I argue in $\S \S 4 \& 6)$. So, either way, at least one non-redundant premise of Ney's argument for $(\boldsymbol{C})$ is unsupported, so the argument doesn't warrant inference of the truth of $(\boldsymbol{C})$. It is consequently not established that difference-making analyses of causation lack metaphysical depth. Indeed the arguments of $\S 6$ show that there is prima facie reason to think that $(\boldsymbol{C})$ is false - to think, in other words, that causation is fundamentally a matter of difference-making.

\section{Physical Causation and Difference-Making}

In order to explicate the notions of facts about 'difference-making' and facts about 'physical causation', Ney distinguishes two approaches to the analysis of causation:

"When it comes to the task of providing a philosophical account of causation, two kinds of projects are typically pursued. First, there are those who seek out a physical account of causation. The project in this case is largely empirical. Look to our fundamental, scientific theories and attempt to discover those features that might characterize all actual, causal relations [...]. In contrast, and more commonly these days, there are those who pursue difference-making accounts of causation. These philosophers try to provide an account of our concept of causation (though not always a reductive analysis). In general, the aim is to 
provide an account that captures the truth or assertability of most of the causal claims we make in ordinary circumstances." (Ney, pp. 737-8; my italics)

Ney's descriptions of the methods adopted by those seeking physical and difference-making accounts correspond, respectively, to Dowe's (2000, Ch. 1) characterizations of the projects of empirical and conceptual analysis. As Dowe describes it, empirical analysis involves an $a$ posteriori investigation, informed by fundamental physical theory, of what all actual cases of causation have in common (ibid. esp. pp. 3-4). Conceptual analysis, on the other hand, is a relatively a priori project the primary data for which are not the deliverances of physical theory but rather linguistic intuitions concerning the applicability of our causal concepts (ibid. esp. pp. 2-3).

As noted in $\S 2$, the supposition that a difference-making account is an approximately correct conceptual analysis helps to explain why Ney thinks her thesis that difference-making facts depend upon facts about physical causation deserves to be called 'foundationalism'. Our ordinary and special scientific causal claims concern the interactions of medium-sized dry goods (to use J. L. Austin's phrase). If it turns out that (as Ney appears to hold, p. 761) such claims roughly track difference-making facts, then showing that these difference-making facts depend upon facts about physical causation (that is, causal facts discovered by physics, the nature of which we might hope an empirical analysis will tell us about) would be tantamount to showing that there is a physical basis for those ordinary and special scientific claims (which is the causal foundationalist thesis as Woodward characterizes it). This, at any rate, seems to be Ney's reasoning (see p. 743, and esp. p. 743n).

When Ney speaks of difference-making theories of causation, she has in mind theories of the sort described in the introduction to this paper. Thus, Ney (pp. 738-9) distinguishes 


\section{Luke Glynn}

counterfactual and probabilistic varieties of difference-making account and (pp. 738, 738n) cites the accounts of Lewis (1973a, 2000) and Yablo (2004) as examples of counterfactual theories. ${ }^{13}$ When Ney speaks about difference-making facts, she has in mind facts about counterfactual or probabilistic (or - we might add on her behalf - nomic) difference-making.

On the other hand, facts about physical causation are those facts deemed causal by a correct empirical analysis of causation (Ney, p. 739). Some care is needed here. Ney takes the clause that follows the comma in the previous-but-one sentence to express a necessary truth: she takes 'physical causal facts' simply to be defined as 'those facts, whatever they may be, that are deemed causal by a correct empirical analysis of causation'. ${ }^{14}$

Care is needed because there is another possible interpretation: it might be supposed that 'facts about physical causation' is to be defined in some other way (perhaps as 'physical process facts'), with the claim that facts of this sort are deemed causal by a correct empirical analysis expressing an alleged contingent truth.

The former, and not the latter, is the correct interpretation of what Ney means by 'facts about physical causation'. ${ }^{15}$ This is confirmed by the fact that Ney defines physical theories of causation synonymously with empirical analyses (e.g., p. 738n, p. 747n), and takes facts about physical causation to be (by definition) those facts deemed causal by a (correct) physical theory of causation (pp. 737-8, 739-40). It is further confirmed when she suggests that physical accounts are those that seek to discover the nature of "physical causation, whatever that comes to" by the method of "looking to our scientific theories" (p. 760). This indicates that she does not intend an a priori, definitional equation of facts about physical causation with physical process facts. Still, Ney sometimes appears to assume - perhaps taking the work of Dowe and others as evidence - that a correct empirical analysis (at least for our world) will not be a difference- 
making account, and that it will incorporate at least some of the standard elements of a process account (see, for example, pp. 740, 752, 755-6).

Given that Ney intends to define 'facts about physical causation' as 'those facts deemed causal by the correct empirical analysis of causation', her causal foundationalist thesis $(\boldsymbol{C F})$ becomes:

(CF1) Difference-making facts depend upon the facts about physical causation (viz. those facts deemed causal by the correct empirical analysis of causation).

The reading of 'facts about physical causation' that yields $(\boldsymbol{C F 1})$ is one that renders the proposition $(\boldsymbol{P})$ equivalent to $(\boldsymbol{P 1})$ :

(P1) Difference-making facts are not among the facts about physical causation (viz. those facts deemed causal by the correct empirical analysis of causation).

It should be noted that $(\boldsymbol{P 1})$ is not analytic since it is not analytic that the correct empirical analysis of causation is not a difference-making account. The contrary is surely a priori possible. ${ }^{16}$ For all we know a priori, it could be the case that, when we look closely enough at our best physical theories, all we will find is difference-making. ${ }^{17}$ If this possibility were realized, then $(\boldsymbol{P 1})$ would be false.

It is straightforward to see that, because of the non-analyticity of $(\boldsymbol{P} 1),(\boldsymbol{C F} 1)$ fails to imply the conclusion $(\boldsymbol{C})$ that Ney takes to follow from her causal foundationalism (p. 758):

(C) Causation is not fundamentally a matter of difference-making.

In order to get a valid argument from $(\boldsymbol{C F 1})$ to $(\boldsymbol{C}),(\boldsymbol{P} 1)$ itself must be added as a supplementary premise. Since $(\boldsymbol{P 1})$ is non-analytic, its truth can only be established a posteriori by establishing 


\section{Luke Glynn}

(a posteriori) that the correct empirical analysis is not a difference-making analysis. But Ney provides no evidence for the a posteriori truth of this proposition. Perhaps she takes others (including Dowe) to have already established it. If so, she is not explicit about this. But, in any case, I shall argue in $\S 6$ that there are good reasons for thinking $(\boldsymbol{P 1})$ to be false. Ney is therefore not entitled to rely on it in inferring $(\boldsymbol{C})$.

Suppose, on the other hand, that instead of taking (as Ney does) 'facts about physical causation' to be defined as 'those facts, whatever they may be, that are deemed causal by the correct empirical analysis', one simply stipulated the meaning of 'facts about physical causation' in such a way as to exclude difference-making facts from counting as physical causal facts. Specifically, one might stipulate that 'facts about physical causation' is to be understood as meaning 'process facts', and follow Dowe (2000) and Salmon $(1994,1997)$ in claiming that the latter notion is not to be understood in difference-making terms. If one were to define 'facts about physical causation' in this way, then Ney's causal foundationalist thesis $(\boldsymbol{C F})$ would become (CF2):

(CF2) Difference-making facts depend upon the facts about physical causation (viz. the process facts [where 'process fact' is not to be understood in difference-making terms]).

(As before, the text in rounded brackets serves to indicate the relevant reading of 'facts about physical causation'. The text in square brackets indicates the relevant reading of 'process fact'.) Now ( $\boldsymbol{C F 2}$ ), unlike ( $\boldsymbol{C F 1})$, implies $(\boldsymbol{C})$ without further supplementation. This is because the reading of 'facts about physical causation' that yields it is one that renders $(\boldsymbol{P})$ equivalent to the analytic (P2): 
(P2) Difference-making facts are not among the facts about physical causation (viz. the process facts [where 'process fact' is not to be understood in difference-making terms]).

But, although $(\boldsymbol{C F 2})$ entails $(\boldsymbol{C}),(\boldsymbol{C F 1})$ and not $(\boldsymbol{C F 2})$ is the causal foundationalist thesis defended by Ney. As shall be seen in the following two sections, Ney's arguments for causal foundationalism do not at all support $(\boldsymbol{C F 2})$. They do provide some support for (CF1), but (CF1) requires supplementation by the unsupported $(\boldsymbol{P 1})$ in order to entail the conclusion $(\boldsymbol{C})$. Ney's arguments for causal foundationalism therefore do not justify the inference of $(\boldsymbol{C})$, the conclusion that implies that difference-making theories of causation lack metaphysical depth.

\section{Ney's Principal Argument for Causal Foundationalism}

When it comes to considering "positive arguments that may be offered for causal foundationalism" (p. 757), Ney says that:

"The most compelling kind of argument is based on the physicalist point [...] that physics does not just provide us with a comprehensive account of what exists in the universe but an account as well of why these events occur. That is, physics provides us with not only an ontology and laws for allowable synchronic states, but dynamical laws as well. These laws single out those features of systems that are causally relevant to the production of effects. So, as physicalists who recognize that physics has this role, we should prefer causal foundationalism." (Ibid.; see also pp. 740-1)

It is important to be clear about what the 'physicalist point' appealed to by Ney does and what it does not show. This point - that physics provides us with dynamic laws that provide information 


\section{Luke Glynn}

about causal relevance - may go some way toward supporting the thesis that the causal claims of common sense and the special sciences are not entirely without foundation in physics (and may thus count against an extreme anti-foundationalism). It may also go some way to supporting the view that the project of empirical analysis is likely to be a fruitful pursuit. If physical theory is not entirely silent on issues of causal relevance, then we may usefully look at physics to see what all and only those interactions that by its lights are causal have in common. If ordinary causal claims have some sort of foundation in physics, and this foundation can be revealed by empirical analysis, then (provided that ordinary, high-level, causal claims are construed as concerning difference-making facts) we might be optimistic that some sort of case can be made for (CF1) the thesis that facts about difference-making depend upon physical causal facts (viz. those facts deemed causal by the correct empirical analysis of causation).

But the physicalist point does not at all support the view that the causal foundation revealed by a correct empirical analysis will turn out to consist in anything other than relations of difference-making (it does not, for example, support the view that the correct empirical analysis will turn out to be a process account, where processes are to be analyzed in nondifference-making terms). Someone who believes that a difference-making account is likely to turn out to be the correct empirical analysis can readily agree that the dynamic physical laws generate a causal foundation, the nature of which may be revealed by empirical analysis, but will presumably insist that the nature of that foundation consists in patterns of (nomic, counterfactual, or probabilistic) difference-making that obtain in virtue of those laws.

So while this physicalist argument, which Ney describes as the 'most compelling' argument for causal foundationalism, perhaps provides some support for $(\boldsymbol{C F 1})$, it provides no support at all for $(\boldsymbol{C F 2})$ - the thesis that facts about difference-making depend on physical causal facts (viz. 
process facts [where 'process fact' is not to be understood in difference-making terms]) - or indeed for any thesis asserting a dependence of difference-making facts upon causal facts that aren't difference-making facts. But, as already noted, only a causal foundationalist thesis of the latter sort implies $(\boldsymbol{C})$ - that causation is not fundamentally a matter of difference-making without further supplementation. $(\boldsymbol{C F 1})$ requires supplementation by the unjustified $(\boldsymbol{P 1})$. So, in the absence of some further argument for a thesis along the lines of $(\boldsymbol{C F 2})$, or for $(\boldsymbol{P 1})$, it seems that Ney is not warranted in taking anything that she has argued for to imply the truth of $(\boldsymbol{C})$.

Ney does describe two additional arguments for her brand of causal foundationalism. She regards these arguments as merely 'supplementary' (p. 757) to the main physicalist argument described above. She even says that she doesn't wish to endorse the second of them (p. 759n), but merely mentions it "because it has been historically important" (p. 758). Nevertheless, it is worth giving some consideration to these arguments to see if they can provide the needed support for a thesis along the lines of $(\boldsymbol{C F 2})$.

\section{Supplementary Arguments}

The first of the supplementary arguments described by Ney is as follows (pp. 757-8). As noted in $\S 1$, pre-emption examples are often deployed in the literature in an attempt to show the extensional inadequacy of difference-making analyses of causation. Sophisticated differencemaking analyses have the resources to deal with at least some such cases. Still, Ney argues that there are cases in which the obtaining of difference-making relations seems simply irrelevant to whether or not there is causation. The attempt to deliver a difference-making analysis of causation therefore seems misguided. In an effort to show this, Ney appeals to the following example given by Tim Maudlin: 


\section{Luke Glynn}

"Suppose you know that the laws that govern a world are the laws of Newtonian mechanics. And suppose you also know that forces in this world are all extremely short range: forces exist only between particles that come within an angstrom of each other. And suppose particle $P$ is at rest (in an inertial frame) at $t_{0}$ and moving at $t_{1}$, and that in the period between $t_{0}$ and $t_{1}$ only one particle, particle $Q$, came within an angstrom of $P$. Then, I claim, we know with complete certainty what caused $P$ to start moving: It was the collision with $Q . "$ (Maudlin 2004, pp. 420-1)

Maudlin claims that we know that the collision with $Q$ was the cause of $P$ 's movement, even though we do not know what would have happened if $Q$ had not collided with $P$. He observes that it is compatible with the above specification of the example,

"[...] that the vicinity of our particles is chock-a-block full of monitoring equipment, which tracks the exact trajectory of $Q$, and jammed with particlelaunching devices loaded with particles just like $Q$ and designed to launch these particles so as to collide with $P$ just as $Q$ did if $Q$ should deviate in any way from its path." (Ibid. p. 421)

Maudlin (ibid.) observes that, in the absence of knowledge about whether or not the particledetection and launching devices are present, we do not know whether $P$ 's movement counterfactually depends upon the collision with $Q$. Still, doubt over whether this counterfactual dependence obtains is simply irrelevant to the judgment that there is causation.

"[N]one of this has anything at all to do with the fact that the collision with $Q$ is what caused $P$ to move. The existence of the monitoring devices and potential backup particles is simply irrelevant to the claim that the collision with $Q$ was the 
cause. In fact, once we know the laws we don't even care what would have happened if $Q$ had not collided with $P[\ldots] . "$ (Ibid.)

It seems that the laws and the intrinsic features of the sequence are enough to determine that the case is one of causation, and the details of extrinsic features (such as whether any pre-empted backups exist) that determine whether or not the case involves counterfactual dependence are irrelevant to its causal status. ${ }^{18}$

Ney (p. 758) takes the fact that there are cases (such as Maudlin's) in which the differencemaking facts seem irrelevant to the causal facts to show that causation is not fundamentally a matter of difference-making. Indeed, she claims that Maudlin's example supports causal foundationalism because "[a]ccording to the foundationalist, causation is not fundamentally a matter of difference-making" (ibid.).

The claim that Maudlin's example supports causal foundationalism seems incorrect. After all causal foundationalism, at least on Ney's construal $(\boldsymbol{C F})$ (for present purposes the distinction between $(\boldsymbol{C F 1})$ and $(\boldsymbol{C F 2})$ is not critical), is the thesis that difference-making facts depend on physical causal facts. Yet what Maudlin's example seems to show is the irrelevance of difference-making facts to causal facts, not their dependence on a certain class of causal fact viz. physical causal facts.

Still, whether or not examples like Maudlin's support causal foundationalism, Ney is surely correct in claiming that they bear on the conclusion $(\boldsymbol{C})$. If such cases show that causation is not a matter of difference-making, they presumably show that $(\boldsymbol{C})$ - it is not fundamentally a matter of difference-making.

But it is not clear that examples like Maudlin's do show that causation is not a matter of difference-making. It is true that, in Maudlin's example, we are not given enough information to 


\section{Luke Glynn}

determine whether or not the movement of $P$ straightforwardly counterfactually depends upon the collision with $Q$ : knowledge of the latter would require information about such extrinsic factors as the presence of particle-launching devices. It is also true that the information we are given, which concerns the laws and the intrinsic nature of the sequence, allows us to judge with certainty that the collision with $Q$ was a cause of the motion of $P$. It consequently seems that causation cannot be a matter of straightforward difference-making. Still it is not true that we are not given enough information to infer any difference-making facts. On the contrary, the information that Maudlin provides is sufficient to allow us to infer the existence of a subtle, de facto, difference-making relation between the collision of $Q$ with $P$, and the subsequent movement of $P$.

Specifically, in his initial presentation of the example, Maudlin gives us the information that (i) particle $P$ is at rest (in an inertial frame) at $t_{0}$ and moving at $t_{1}$; (ii) the laws that govern the relevant world are the laws of Newtonian mechanics (so that particle $P$, which is at rest at $t_{0}$, will remain at rest unless some force acts upon it); (iii) forces exist only between particles that come within an angstrom of each other; and (iv) between $t_{0}$ and $t_{1}$ only particle $Q$ came within an angstrom of $P$. But this is precisely enough information to establish that there is a feature of the actual circumstances (namely the absence of any particles other than $Q$ within an angstrom of $P$ during the $\left[t_{0}, t_{1}\right]$ interval) which, when held fixed, renders the movement of $P$ dependent on the collision with $Q$, as revealed by the (true) ENF counterfactual if $Q$ hadn't collided with $P$ and there (still) hadn't been any other particles within an angstrom of $P$ between $t_{0}$ and $t_{1}$, then $P$ would not have been moving at $t_{1}$.

Since Maudlin's initial presentation of the example furnishes us with enough information to judge that the collision with $Q$ de facto made a difference to the movement of $P$, it does not 
suffice to show that such judgments are irrelevant to causal judgments, and that causation is not (fundamentally) a matter of de facto difference-making. Interestingly, the example illustrates that facts about laws and the intrinsic features of a sequence can be enough to determine the existence of de facto difference-making, even though they are not enough to determine whether or not there is straightforward difference-making. De facto difference-making accounts are thus relatively well placed to accommodate the intrinsicness intuition without departing from the difference-making paradigm (see Hall and Paul 2003, pp. 124-7).

The second supplementary argument for causal foundationalism described by Ney (ibid., pp. 758-9) appeals to some prima facie reasons for thinking that facts about difference-making aren't objective. Since causation seems to be an objective relation, it is concluded that causation cannot be fundamentally a matter of difference-making. Just like the previous argument, this argument provides no obvious support for $(\boldsymbol{C F})$, the thesis that difference-making facts depend upon physical causal facts (again, the distinction between $(\boldsymbol{C F 1})$ and $(\boldsymbol{C F 2})$ is not critical for present purposes). Indeed, the present argument may actually count against $(\boldsymbol{C F})$. For if facts about physical causation are taken to be objective, then demonstrating that patterns of difference-making are less than fully objective may make it harder rather than easier to show them to be grounded in facts about physical causation.

But, once again, although the thesis that difference-making facts are not fully objective does not provide clear support for causal foundationalism, it does rather directly bear upon Ney's conclusion $(\boldsymbol{C})$ - that difference-making facts are not among the fundamental causal facts and, more generally, it bears upon the question of whether difference-making theories of causation are metaphysically deep. It is therefore worth briefly considering the arguments Ney describes for the non-objectivity of difference-making facts. 


\section{Luke Glynn}

The first such argument concerns probabilistic difference-making, and appeals to the claim that the reference-class problem shows there not to be an objective fact of the matter about whether one event makes a probabilistic difference to the occurrence of another (p. 759). The second concerns counterfactual difference-making accounts, and appeals to the claim that the truth-values of ordinary counterfactuals are typically indeterminate (ibid.).

There are perfectly reasonable things that the difference-making theorist can say in defense of her position here. First, it is not at all clear that the reference-class relativity of probability shows probabilistic difference-making relations to be less than fully objective. Provided the reference-classes in question are themselves objective, it would seem that reference-class relativized probabilities are too. ${ }^{19}$ It is therefore open to the difference-making theorist to acknowledge the reference-class relativity of probability, and say either (a) that causation is itself reference-class-relative; ${ }^{20}$ or (b) that there is some reference-class (perhaps the most specific one ${ }^{21}$ ) such that probabilistic difference-making relative to that reference class is uniquely relevant to whether a case is one of causation.

Second, David Lewis has made a concerted attempt to show that there is an objective fact of the matter about how counterfactuals must be evaluated in order to obtain the results required by a counterfactual difference-making account of causation. According to Lewis, the interpretation of counterfactuals involves a set $W$ of possible worlds, a binary 'accessibility' relation $R$ defined over the members of $W$, and a ternary relation $\leq_{i}$ over $W$, where $j \leq_{i} k$ is understood as meaning that "the world $j$ is at least as similar to the world $i$ as the world $k$ is" (Lewis $1973 b$, p. 48) and where, for every $i \in W$, the relation $\leq_{i}$ constitutes a weak ordering of the possible worlds in $W$ (ibid.). 
On Lewis's (1973a, p. 560; 1973b, p. 49; 1979, p. 465) semantics, a counterfactual $\phi \square \rightarrow$ $\psi$ is true at a world $i \in W$ (according to a comparative similarity relation $\leq_{i}$ ) iff either (1) there is no world $j \in W$ accessible from $i$ at which $\phi$ is true (the vacuous case), or (2) there is a world $j \in$ $W$ accessible from $i$ at which $\phi \& \psi$ is true and which is such that, for every world $k \in W$ at which $\phi \& \sim \psi$ is true, $\sim\left(k \leq_{i} j\right){ }^{22}$

The set $W$ is to be taken as the set of all possible worlds, of which Lewis takes there to be an uncountable infinity (1986c, pp. 118, 133), which exhaust logical space (1986c, pp. 86, 87), and the character of the totality of which is fixed and immutable. ${ }^{23}$ Counterfactuals themselves are context-sensitive. Lewis $(1979$, p. $465 ; 1973 b$, pp. 92-4) takes this to be reflected in the context-sensitivity of the relation $\leq_{i}$. Nevertheless, fixing a context fixes the relation $\leq_{i}$, and determines truth-values for counterfactuals (1973b, p. 93). Thus counterfactuals have objective truth-values relative to a context (ibid.).

Lewis claims that there is a specific kind of context (and hence relation $\leq_{i}$ ) that is uniquely relevant to the evaluation of what causes what: namely, 'ordinary' contexts (which yield what he calls the "standard resolution of vagueness" of counterfactuals (1979, p. 457; see also p. 458)). He describes (ibid., p. 472) a system of "weights or priorities" that he takes to govern the similarity relation $\leq_{i}$ in operation in such contexts. Causation is to be analyzed in terms of those counterfactuals that come out true according to such a similarity relation (ibid., p. 459; 2004, p. 78). While Lewis doesn't take his "weights or priorities" to uniquely fix a relation $\leq_{i}(1979, \mathrm{p}$. 472), he claims that the remaining indeterminacy of comparative overall similarity is in fact reflected in (limited) indeterminacy of the causal relation (1973a, p. 560). If Lewis is right, then the counterfactual difference-making relations appealed to by counterfactual analyses of causation do not suffer from a problematic lack of objectivity. 


\section{Luke Glynn}

So while the 'subjectivity' argument bears rather directly on the issue of whether causation is fundamentally a matter of difference-making, reasonable doubts may be raised about its central premise that there aren't objective facts about difference-making. It is because Ney recognizes this that she doesn't endorse the argument (pp. 759, 759n).

Since neither of the supplementary arguments described by Ney is conclusive in establishing $(\boldsymbol{C})$, much turns on her principal 'physicalist' argument, discussed above. Unlike the supplementary arguments this is correctly regarded as, in the first place, an argument for causal foundationalism rather than an argument directly for $(\boldsymbol{C})$. But, as has already been seen, it only supports a version of causal foundationalism (namely $(\boldsymbol{C F 1})$ ) that fails on its own to entail $(\boldsymbol{C})$. The premise $(\boldsymbol{P 1})$, which is the needed supplement to $(\boldsymbol{C F 1})$ in a valid argument for $(\boldsymbol{C})$, is one that Ney leaves unsupported. It shall now be argued that she is not entitled simply to take it for granted.

\section{Are Difference-Making Facts Among the Physical Causal Facts?}

It has been suggested $(\S 3)$ that the reason that Ney does not build a case for $(\boldsymbol{P 1})$ - the needed supplement for $(\boldsymbol{C F 1})$ in a valid argument for $(\boldsymbol{C})$ - may be that she takes it to be supported by the work of Dowe and others. The principle $(\boldsymbol{P 1})$, recall, states that difference-making facts are not among the facts about physical causation (viz. the facts deemed causal by the correct empirical analysis).

But there are good reasons for thinking that $(\boldsymbol{P 1})$ is very far from having been established. In particular, there are good reasons to think that any extensionally adequate, non-circular process theory of causation will have to appeal to difference-making facts, especially when it comes to making the important distinctions between, on the one hand, the genuinely causal processes and interactions that the process theorist invokes in analyzing token causation (see 
Dowe 2000, Ch. 7; and Salmon 1984, pp. 178-9) and, on the other hand, so-called "pseudoprocesses" (Salmon 1984, p. 141) and (mere) space-time intersections. Consequently, even if some process theory does turn out to be the correct empirical analysis (and such theories seem to be the main rivals to pure difference-making analyses), it will plausibly be one that includes difference-making facts among the facts that it deems causal. Indeed, it will plausibly be one that deems difference-making facts to be more basic than process-facts.

To see this, it is worth examining (albeit necessarily briefly), the most influential existing process theories of causation: namely those due to Salmon $(1984,1994,1997)$ and Dowe (1992, 2000). Dowe's theory can be summarized in two propositions (Dowe 2000, p. 90; cp. also Dowe 1992, p. 210):

DCQ1. A causal interaction is an intersection of world lines that involves exchange of a conserved quantity.

DCQ2. A causal process is a world line of an object that possesses a conserved quantity.

An exchange of a conserved quantity is defined (Dowe 2000, p. 92; see also Dowe 1992, p. 210) as occurring "when at least one incoming, and at least one outgoing process undergoes a change in the value of the conserved quantity" (the exchange being governed by the relevant conservation law).

The trouble with Dowe's definition DCQ2 of a causal process (a problem that infects his definition DCQ1 of a causal interaction due to the fact that the notion of an exchange is defined in terms of that of a process) is that it relies upon a notion of diachronic object identity, and the most plausible accounts of the latter are themselves causal (cp. Choi 2002, pp. 116-17). This presents a dilemma: either the notion of causality involved in the analysis of diachronic object 


\section{Luke Glynn}

identity is itself to be analyzed in terms of processes, leading to circularity or regress, or it is to be analyzed in difference-making terms, with the resulting account deeming facts about difference-making to be causal (and indeed to be causal facts that are more basic than causal process facts). Dowe (ibid. pp. 101-9) seeks to avoid this dilemma by presenting some rivals to the causal theory of diachronic object identity (pp. 102-4) and presenting some arguments against the causal theory (pp. 104-7). While this is not the occasion to go into the details, Dowe's arguments against the causal theory are far from compelling, while the rivals he presents seem to be subject to even worse objections. ${ }^{24}$

On the other hand, Salmon's $(1984$, pp. 148, 171) criteria for distinguishing genuine causal processes and interactions from pseudo-processes and (non-causal) space-time intersections are formulated in explicitly counterfactual terms. More recently, Salmon $(1994,1997)$ has attempted formulate criteria that do not make use of counterfactuals. Salmon (influenced by Dowe 1992, pp. 210-15) takes over Dowe's definition DCQ1 of causal interactions (see Salmon 1997, p. 468; cp. Salmon 1994, p. 303), but defines the notion of a causal process somewhat differently:

SCQ2. A causal process is the world-line of an object that transmits a nonzero amount of a conserved quantity at each moment of its history (each spacetime point of its trajectory) (Salmon 1997, p. 468, italics modified; cp. Salmon 1994, p. 308)

Salmon defines the notion of transmission that figures in SCQ2 as follows:

SCQ3. A process transmits a conserved quantity between $A$ and $B(A \neq B)$ if and only if it possesses (a fixed amount of) this quantity at $A$ and at $B$ and at every stage of the process between $A$ and $B$ without any interactions in the open interval $(A, B)$ that 
involve an exchange of that particular conserved quantity. (Salmon 1997, p. 462, italics modified; cp. Salmon 1994, p. 308)

This more recent account of Salmon's is not successful. Hitchcock (2009, pp. 78-9; cp. Hitchcock 1995, pp. 314-15) presents the following counterexample.

Suppose there are two objects, $a$ and $b$. Object $a$ is composed of two parts. Initially, $b$ is at rest and $a$ is moving toward $b$; $a$ then collides with $b$ and one part of $a$ detaches from the other and becomes attached to $b$. In addition, momentum is transferred from the diminished object $a$ to the augmented object $b$, so that $a$ comes to rest and $b$ starts to move. Throughout this sequence, the objects are casting shadows on a metallic plate with uniform nonzero charge density. The total area of the shadows remains constant throughout.

Consider the shadow cast by $a$. Let $T G_{a}$ ( $T G$ for time-wise gerrymander) be the mereological sum of darkened regions of the plate taken for the time at which they are in $a$ 's shadow. Let $T G_{b}$ be the mereological sum of darkened regions of the plate taken for the time at which they are in $b$ 's shadow. The 'objects' with world-lines $T G_{a}$ and $T G_{b}$ possess a constant amount of charge (a conserved quantity) during the periods before and after the collision between $a$ and $b$ (because the area of these 'objects' is constant and the charge density of the plate is uniform). Moreover, during these periods, $T G_{a}$ and $T G_{b}$ do not engage in any interactions involving the exchange of charge. They therefore count as transmitting charge during these periods according to SCQ3, and hence are (incorrectly) counted as causal processes by SCQ2 (see Hitchcock 2009, p. 85). At the intersection of the world lines of these two 'processes', charge is exchanged between them: the charge of $T G_{a}$ decreases (because the area of $a$ 's shadow decreases), and the charge of $T G_{b}$ increases by the same amount. Definition DCQ1 thus appears (incorrectly) to count the intersection of $T G_{a}$ and $T G_{b}$ as a causal interaction. ${ }^{25}$ 


\section{Luke Glynn}

Salmon's earlier (1984) account succeeds in excluding $T G_{a}$ and $T G_{b}$ from counting as transmitting charge, and hence from counting as causal processes. But that is only because his earlier definition of 'transmission' appeals to counterfactuals (cp. Hitchcock 1995, p. 315). On that earlier theory, $T G_{a}$ and $T G_{b}$ don't count as charge-transmitting processes because a local modification of the charge of $T G_{a}$ or $T G_{b}$ would not result in its manifesting differing charges at space-time points beyond the point of local modification in the absence of further local modifications (Salmon 1984, p. 148).

On the assumption that $T G_{a}$ and $T G_{b}$ are not world lines of genuine objects (but rather time-wise gerrymanders), Dowe's definition DCQ2 also excludes them from counting as causal processes (see Salmon 1997, p. 472; and Hitchcock 2009, p. 80). But both Salmon (1997, p. 472) and Hitchcock (2009, pp. 80-4) object to Dowe's reliance on an unanalyzed notion of diachronic object identity in excluding them from counting as such. ${ }^{26}$ Indeed, as already noted, it is plausible that the latter notion must be understood in difference-making terms.

The upshot of all this is that Ney is wrong if she thinks that it can simply be taken as established that the correct empirical analysis of causation is a process analysis that has no need to appeal to difference-making facts. She is consequently wrong if she thinks that $(\boldsymbol{P 1})$ does not stand in need of argument.

In fact, there is some evidence that Ney herself finds plausible an empirical analysis on which $(\boldsymbol{P 1})$ is actually false. Although Ney neither endorses any specific existing empirical account of causation (such as those given by Dowe and Salmon), nor seeks to develop in detail her own, some brief remarks suggest that she is sympathetic to a process account that cashes out the notion of a causal process in terms of relations of lawful determination (p. 753, esp. p. 753n). Of course she accepts that it is not plausible to 
"[...] think of determination as being equivalent to the causal relation. In general what gets determined by the laws are states of entire systems. Causes may be parts of these systems, or parts of these systems that have particular features [...]." (p. 753)

She notes that such an account "of physical causation owes a lot to the account of causation found in Mill [...], revised by Mackie [...] and then by Strevens" (p. 753n).

Yet, if such an empirical analysis is correct, it seems that $(\boldsymbol{P 1})$ - the proposition that difference-making facts are not among the physical causal facts (viz. the facts deemed causal by the correct empirical analysis of causation) - is false. For, as was noted in $§ 1$, accounts within this nomic regularity tradition are naturally regarded as difference-making accounts. On the accounts of Mill (1973/1843), Mackie (1965), and Strevens (2007), a cause $c$ is a non-redundant part of an antecedent set $S$ of conditions that sufficed for the effect $e$. The non-redundancy ensures that the cause makes a difference: without $c, S$ wouldn't have sufficed for $e$. This is the reason why Strevens - who besides Dowe is Ney's main example of someone advancing a physical theory of causation - regards such accounts as "vindicating the difference-making intuition" (Strevens 2007, p. 95, see also p. 97).

The sort of empirical account to which Ney seems sympathetic is one that - like the accounts of causation given by Strevens (2007) and Mackie (1980, pp. 44-7, 218-29) comprises process, as well as nomic difference-making elements. But even though such an empirical account may not be a pure difference-making theory, subscribing to it would still be incompatible with maintaining (P1). For it still deems difference-making facts to be among the (basic) causal facts. Indeed it is plausible that, on such an account, the difference-making facts must be taken to be more basic than the process facts (cp. Strevens 2007, pp. 109-10; Psillos 


\section{Luke Glynn}

2002, pp. 109-10). Given the difficulties (attested to by the efforts of Salmon and Dowe) of analyzing the notion of a causal process in non-difference-making terms, it is hardly surprising that this should be so. ${ }^{27}$

\section{Conclusion}

I have examined Ney's novel argument for the inadequacy of difference-making theories of causation. Unlike standard arguments for this conclusion, Ney's does not rest primarily upon appeal to pre-emption cases and, indeed, is not principally an argument for the extensional inadequacy of difference-making theories. Rather, it is an argument for the conclusion that such theories lack metaphysical depth, in the sense that the facts in terms of which they analyze causation are not basic causal facts. Ney's argument is also interesting in that it connects two important recent debates in the philosophy of causation in a novel way. Specifically, its premise $(\boldsymbol{C F})$ concerns the truth of a version of causal foundationalism, while its conclusion $(\boldsymbol{C})$ bears on the debate between difference-making theorists and their opponents.

I have argued that, for all its interesting novelty, Ney's argument is ultimately unsuccessful. Indeed the arguments of $\S 6$ to some extent count directly against $(\boldsymbol{C})$. Those arguments involved giving reasons for thinking that process-theories - the most popular rivals to pure difference-making analyses - must themselves invoke difference-making in analyzing causal processes and interactions. If this is the case, then causal process facts are not among the most basic causal facts, but rather difference-making facts are still more basic. This may supply at least a presumption that difference-making facts are the most basic sort of causal fact. The question of whether causal foundationalism is true then becomes a question of whether 
difference-making facts have a basis in physics. This highlights the fact that the debate over difference-making theories and that over causal foundationalism are importantly connected, even though Ney is perhaps wrong to think that the connection can be exploited for the purpose of showing that difference-making theories lack metaphysical depth.

${ }^{1}$ This tradition dates back at least to Hume (1978/1739-1740).

${ }^{2}$ The classic statement of a counterfactual analysis is due to Lewis (1973a). But Lewis's original analysis is more sophisticated than the simple theory described in the main text, identifying causation not with simple counterfactual difference-making but rather with its ancestral.

${ }^{3}$ Classic probabilistic analyses are given by Reichenbach (1971/1956), Good (1961a, 1961b) and Suppes (1970). But even on these classic analyses, only those probabilistic difference-making relations that remain once past history is held fixed (to eliminate the influence of common causes) are taken to be causal. Similarly for more recent probabilistic analyses, such as those given by Eells (1991) and Ramachandran (2004).

${ }^{4}$ Mill's (1973/1843) regularity theory contains a similar non-redundancy requirement. He requires "the concurrence of all of them [i.e. the elements of $S$ ] being requisite to produce" $e$ (p. 327). (Though Mill actually identifies the "real Cause" (ibid., p. 328) of $e$, not with $c$, but with the set $S$.) See Hume (op. cit. Bk. I, Part iii) for what is taken to be the classic statement of a regularity analysis, and see Strevens (2007) and Baumgartner (ms.) for state-of-the-art versions.

${ }^{5}$ The best known such accounts are due to Salmon (1984) and Dowe (2000).

${ }^{6}$ A key question for proponents of the de facto dependence approach is whether the factors to be held fixed $\left(b\right.$ or $b_{1}, \ldots$, and $b_{n}$ ) can be identified without appealing to causal facts (cp. Maudlin 2004, pp. 422-3). While I cannot do justice to that issue here, it is noteworthy that there is a flourishing literature of attempts to specify the relevant factors using structural equation models 
(Pearl 2009, Ch. 10; Hitchcock 2001a, 2007b; Woodward 2003; Halpern and Pearl 2005; Glymour and Wimberly 2007) or directed independence graphs (Glynn 2011). These encode patterns of counterfactual or probabilistic difference-making, rather than causal relations per se (see Halpern and Hitchcock ms.). The important question is then whether a non-causal account can be given of these counterfactuals and probabilistic dependencies. For divergent views on this question as it pertains to counterfactuals, see Woodward (2003, esp. pp. 133-45) and Glynn (ms.).

${ }^{7}$ Hybrids accounts, combining elements of the difference-making and process approaches, have been proposed (see, for example, Lewis 1986b, pp. 205-7; Menzies 1989; Dowe 2004; and Handfield et al. 2008), though none has gained widespread acceptance. More radically, Hall (2004a; see also his 2000) has argued that the difficulty of developing a univocal analysis of causation is a reflection of the fact that there are two kinds or concepts of causation, one essentially involving counterfactual dependence, the other essentially involving a notion of 'production', his analysis of which (2004a, pp. 257-67) contains both regularity- and processtheoretic elements.

${ }^{8}$ Several of the papers in Price and Corry (op. cit.) endorse intermediate positions. On the one hand, some of the represented authors (e.g. Woodward 2007, pp. 68-70; and Hitchcock 2007a, pp. 55-6) argue that fundamental physical theory makes a limited use of causal notions. On the other hand, some claim that the truthmakers for the causal claims of common sense and the special sciences include, but are not limited to, the fundamental physical laws. For example Loewer (2007) suggests that a probability distribution over initial conditions is also among the truthmakers (see also Field 2003; and Elga 2007), while Woodward (2007), Hitchcock (2007a), and Eagle (2007) argue that ordinary causal claims must be explicated with reference to the 
notion of an intervention, which seemingly is not among (or straightforwardly analyzable in terms of) the concepts of fundamental physical theory (see Price and Corry op. cit., p. 3).

9 Woodward (2007), Hitchcock (2007a), and Eagle (2007) each draw specific conclusions concerning the issue of causal foundationalism on the explicit assumption that an interventionist theory of causation (a species of counterfactual difference-making account) is true. In each case, this assumption is essential to the conclusions they draw.

${ }^{10}$ In a similar vein, Strevens $(2007$, p. 112) says "I concur with Lewis and Mackie, then, that causal claims are claims about difference-making. I do not agree that this difference-making is itself the fundamental causal relation. What is fundamental is the web of causal influence. This is the province of fundamental physics."

Strevens, however, is clear that the sort of difference-making he has in mind is making "a difference between [an] event's occurring and its failing to occur" (ibid.; cp. also Strevens 2004, pp. 158-9). Yet there are more ways to make a difference to an event than by making a difference to whether or not it occurs (or even to its probability of occurrence). Thus Lewis's (2000) analysis of causation in terms of (the ancestral of) a counterfactually defined notion of influence allows that $c$ may be a cause of $e$ provided merely that whether or not $c$ occurs, or the manner of $c$ 's occurrence, makes a difference to the manner of $e$ 's occurrence. Strevens (2007, p. 110) makes clear that the notion of 'causal influence', which he regards as more basic than (what we might call) 'whether or not' difference-making, might have to be understood in Lewis's counterfactually-defined terms.

By contrast, Ney cites Lewis's (2000) analysis as an example of a sophisticated differencemaking account of causation, and indicates that the (subtle) difference-making relations to which it appeals are to be taken to be among those that she is denying that causation fundamentally 
consists in (Ney, p. 738n). Consequently, Ney's critique of the difference-making approach seems to be more radical than Strevens'.

${ }^{11}$ In fact, Ney also thinks that there are reasons for doubting that an extensionally adequate difference-making account can be developed. First, she thinks that a typical event $e$ plausibly has more causes than there are events that make a difference to it (pp. 741-3). Second (as shall be further discussed in $§ 5)$ she thinks that there are cases in which whether or not an event $c$ makes a difference to a distinct event $e$ is simply irrelevant to whether $c$ is a cause of $e$ (pp. 757-8).

${ }^{12}$ It should be noted that most of Ney's paper is devoted to defending $(\boldsymbol{C F})$, rather than arguing for $(\boldsymbol{C})$. Nevertheless, Ney (p. 158) says that $(\boldsymbol{C})$ follows from $(\boldsymbol{C F})$. Showing either that it doesn't, or that Ney's arguments for $(\boldsymbol{C F})$ don't go through, is therefore essential to the vindication of difference-making analyses against the charge of a lack of depth. Given Ney's principal concern in her paper, it would be charitable to attribute to her the interpretation of 'facts about physical causation' such that (though $(\boldsymbol{C F})$ does not support $(\boldsymbol{C})$ ), her arguments for $(\boldsymbol{C F})$ are not beside the point. Indeed, such an interpretation is better supported by the textual evidence.

${ }^{13}$ She doesn't give examples of probabilistic theories, but seems to have in mind accounts such as those mentioned in the introduction and note 3, above. Ney does not include regularity theories among her list of difference-making theories. This point will be further discussed in $\S 6$.

${ }^{14}$ By contrast, although Ney notes (p. 738) that difference-making accounts are frequently offered as conceptual analyses, and takes them to have least prima facie plausibility when considered as such (p. 761), clearly she does not take 'facts about difference-making' to be defined as 'those facts, whatever they may be, that are deemed causal by a correct conceptual analysis'. 
${ }^{15}$ Ney has confirmed this in personal communication.

${ }^{16}$ I assume a priori possibility is a good guide (or at least the best we have) to (non-)analyticity.

${ }^{17}$ Dowe (2000, pp. 11-12) observes that it is a priori possible that a single theory of causation should serve both as a successful conceptual analysis and as a successful empirical analysis. There seems to be no absurdity in the notion that a difference-making theory should do so.

${ }^{18}$ The intuition that a sequence's causal character is determined just by its intrinsic (non-causal) nature, together with the laws that govern it, has been discussed (sympathetically) by Lewis (1986b, pp. 205-7), Hall (2000, pp. 206, 217; 2004a, esp. p. 225; 2004b), and Hall and Paul (2003, pp. 114-23). See also Menzies (1996, pp. 98-100). This intrinsicness intuition is often taken to count against pure difference-making theories of causation (cp. Hall 2004b, pp. 255-6). The intuition is used by Lewis (1986b, pp. 205-7) to justify a departure from a pure counterfactual account, by Menzies (1996, esp. pp. 96-101, 105-15) in departing from a pure probabilistic account, and by Hall $(2004 a, 2004 b)$ to (part-)justify the claim that there is a (central) kind of causation that requires an analysis involving non-difference-making elements.

${ }^{19}$ Hájek (2007) argues that objective chances are reference-class relative.

${ }^{20}$ I think that this is just what the 'level' relativity of causation, which is often appealed to in the debates over mental causation and the status of special scientific causal explanations amounts to. But this is not the place to tell that story.

21 Unless one assumes a naive actual frequentist interpretation of probability - which contemporary defenders of probabilistic analyses of causation would likely reject - there is no reason to suppose probabilities relative to maximally specific reference classes will necessarily be trivial. 
${ }^{22}$ Lewis $(1973 b$, pp. 14, 15-16, 99, 99n, 130) expresses uncertainty about whether the relevant accessibility relation $R$ should be taken as the trivial or "universal" (ibid., pp. 16, 99) accessibility relation such that, for every $i, j \in \mathrm{W}, i R j$. In any case, he (1973b; pp. 67, 91-4; 1979, pp. 465, 472) seemingly takes the context-sensitivity of counterfactuals (at least those relevant to causation) to be wholly accounted for by the context-sensitivity of the relation $\leq_{i}$, without any additional context-sensitivity due to variability of the relation $R$.

${ }^{23}$ As Lewis says, "the character of the totality of all worlds is not a contingent matter" (1986c, p. 126; see also pp. $111-12,125,128,130)$. While Lewis himself is a modal realist, it seems that versions of so-called "ersatz modal realism" (ibid., p. 136; italics original) can emulate the fixed and immutable cardinality of the set of worlds (see ibid., Ch. 3, esp. pp. 144-8, 177, 191).

${ }^{24}$ See Hitchcock (2009, pp. 80-4) for a detailed discussion of the problems that arise for Dowe's account due to his lack of a satisfactory account of identity over time.

${ }^{25}$ While Salmon (1997, p. 473-4) attempts to block this counterexample of Hitchcock's, Choi (2002, p. 111-14) and Hitchcock (2009, p. 87) show that his attempt is unsuccessful.

${ }^{26}$ Though, somewhat ironically, Dowe (2000, pp. 120-1) presents an example that seems to show that Salmon's $(1994,1997)$ account also requires a notion of diachronic object identity in order to distinguish causal interactions from mere space-time intersections.

${ }^{27}$ One suspects that Ney would have to rely heavily upon appeals to nomic difference-making in cashing out her frequent talk of 'physical causal influence' (Ney, pp. 740, 741, 742, etc.) and of 'interaction' (pp. 741, 746, 749, etc.), notions that she supposes an account of physical causation will have at its disposal. 


\section{Acknowledgements}

For very helpful comments and suggestions, I would like to thank Christopher Hitchcock, Thomas Kroedel, Dennis Lehmkuhl, Alyssa Ney, Samuel Schindler, Wolfgang Spohn, Joel Velasco, and two anonymous referees for this journal. Funding for this research was provided by Deutsche Forschungsgemeinschaft grant SP279/15-1 and by the James S. McDonnell Foundation Causal Learning Collaborative.

\section{References}

Baumgartner, M. (ms.). A regularity theoretic approach to actual causation.

Choi, S. (2002). Causation and gerrymandered world lines: a critique of Salmon. Philosophy of Science, 69, 105-117

Collins, J., Hall, N., \& Paul, L. A. (Eds.) (2004). Causation and counterfactuals. (Cambridge, MA: MIT Press)

Dowe, P. (1992). Wesley Salmon's process theory of causality and the conserved quantity theory. Philosophy of Science, 59, 195-216

Dowe, P. (2000). Physical causation. (Cambridge: CUP)

Dowe, P. (2004). Chance-Lowering Causes. (In P. Dowe and P. Noordhof (Eds.), Cause and Chance: Causation in an Indeterministic World (pp. 28-38). London: Routledge.)

Eagle, A. (2007). Pragmatic causation. In Price and Corry (2007), 156-190.

Eells, E. (1991). Probabilistic causality. (Cambridge: CUP)

Elga, A. (2007). Isolation and folk physics. In Price and Corry (2007), 106-119. 


\section{Luke Glynn}

Field, H. (2003). Causation in a physical world. (In M. J. Loux \& D. Zimmerman (Eds.), Oxford handbook of metaphysics (pp. 435-460). Oxford: Oxford University Press.)

Glymour, C. \& Wimberly, F. (2007). Actual causes and thought experiments. (In J. K. Campbell, M. O’Rourke, \& H. Silverstein (Eds.), Causation and explanation (pp. 43-67). Cambridge, MA: MIT Press.)

Glynn, L. (2011). A probabilistic analysis of causation. British Journal for the Philosophy of Science, 62, 343-392

Glynn, L. (ms.). Of miracles and interventions.

Good, I. J. (1961a). A causal calculus (I). British Journal for the Philosophy of Science, $11,305-318$

Good, I. J. (1961b). A causal calculus (II). British Journal for the Philosophy of Science, $12,43-51$

Hájek, A. (2007). The reference class problem is your problem too. Synthese, 156, 563585

Hall, N. (2000). Causation and the price of transitivity. Journal of Philosophy, 97, 198222

Hall, N. (2004a). Two concepts of causation. In Collins et al. (2004), 225-276.

Hall, N. (2004b). The intrinsic character of causation. Oxford Studies in Metaphysics, 1, 255-300

Hall, N. \& Paul, L. A. (2003). Causation and pre-emption. (In P. Clark \& K. Hawley (Eds.) Philosophy of science today (pp. 100-130). Oxford: Clarendon Press.)

Halpern, J. Y. \& Hitchcock, C (ms.). Graded causation and defaults. 
Halpern, J. Y. \& Pearl, J. (2005). Causes and explanations: a structural-model approach. Part I: Causes. British Journal for the Philosophy of Science, 56, 843-887

Handfield, T., Twardy, C. R., Korb, K. B, \& Oppy, G (2008). The metaphysics of causal models: Where's the biff? Erkenntnis, 68, 149-168

Hitchcock, C. (1995). Salmon on explanatory relevance. Philosophy of Science, 62, 304320

Hitchcock, C. (2001a). The intransitivity of causation revealed in equations and graphs. Journal of Philosophy, 98, 273-299

Hitchcock, C. (2001b). A tale of two effects. The Philosophical Review, 110, 361-396

Hitchcock, C. (2007a). What Russell got right. In Price and Corry (2007), 45-65.

Hitchcock, C. (2007b). Prevention, preemption, and the principle of sufficient reason. Philosophical Review, 116, 495-532

Hitchcock, C. (2009). Problems for the conserved quantity theory: counterexamples, circularity, and redundancy. Monist, 92, 72-93

Hume, D. (1978). A treatise of human nature. (L. A. Selby-Bigge and Peter Nidditch (Eds.), Oxford: Clarendon Press.) First published 1739-1740.

Kvart, I. (2004). Causation: probabilistic and counterfactual analyses. In Collins et al. (2004), 359-386.

Lewis, D. (1973a). Causation. Journal of Philosophy, 70, 556-567

Lewis, D. (1973b). Counterfactuals. (Cambridge, MA: Harvard University Press)

Lewis, D. (1979). Counterfactual dependence and time's arrow. Noûs, 13, 455-476

Lewis, D. (1986a). Philosophical papers. (Oxford: Oxford University Press)

Lewis, D. (1986b). Postscripts to "Causation". In Lewis (1986a), 172-213. 


\section{Luke Glynn}

Lewis, D. (1986c). On the Plurality of Worlds. (Oxford: Blackwell)

Lewis, D. (2000). Causation as influence. Journal of Philosophy, 97, 182-197

Lewis, D. (2004). Causation as influence. In Collins et al. (2004), 75-106. (Expanded version of Lewis (2000).)

Loewer, B. (2007). Counterfactuals and the second law. In Price and Corry (2007), 293326.

Mackie, J. L. (1965). Causes and conditions. American Philosophical Quarterly, 2, 245264

Mackie, J. L. (1980). The cement of the universe: a study of causation. (Oxford: OUP)

Maudlin, T. (2004). Causation, counterfactuals, and the third factor. In Collins et al. (2004), 419-443. (Reprinted in T. Maudlin (2007), The metaphysics within physics (pp. 143-169). Oxford: OUP.)

Menzies, P. (1989). Probabilistic causation and causal processes: a critique of Lewis. Philosophy of Science, 56, 642-663

Menzies, P. (1996). Probabilistic causation and the pre-emption problem. Mind, 105, 85117

Mill, J. S. (1973). A system of logic ratiocinative and inductive. (In J.M. Robson (Ed.), Collected works of John Stuart Mill (Vol. VII-VIII). Toronto and Buffalo: University of Toronto Press.) First published 1843.

Ney, A. (2009). Physical causation and difference-making. British Journal for the Philosophy of Science, 60, 737-764

Pearl, J. (2009). Causality: models, reasoning, and inference. $2^{\text {nd }}$ Ed. (Cambridge: Cambridge University Press) 
Price, H. \& Corry, R. (Eds.) (2007). Causation, physics, and the constitution of reality: Russell's republic revisited. (Oxford: Clarendon Press)

Psillos, S. (2002). Causation and explanation. (Chesham, Bucks: Acumen)

Ramachandran, M. (2004). A counterfactual analysis of indeterministic causation. In Collins et al. (2004), 387-402.

Reichenbach, H. (1971). The direction of time. M. Reichenbach (Ed.). (Berkeley, CA: University of California Press). First published 1956.

Russell, B. (1913). On the notion of cause. Proceedings of the Aristotelian Society, 13, 126

Salmon, W. (1984). Scientific explanation and the causal structure of the world. (Princeton, NJ: Princeton University Press)

Salmon, W. (1994). Causality without counterfactuals. Philosophy of Science, 61, 297312

Salmon, W. (1997). Causality and explanation: A reply to two critiques. Philosophy of Science, 64, 461-477

Schaffer, J. (2000a). Trumping preemption. Journal of Philosophy, 97, 165-181

Schaffer, J. (2000b). Causation by disconnection. Philosophy of Science, 67, 285-300

Strevens, M. (2004). The causal and unification approaches to explanation unified causally. Noûs, 38, 154-176

Strevens, M. (2007). Mackie remixed. (In J. K. Campbell, M. O’Rourke and H. S. Silverstein (Eds.), Causation and explanation (pp. 93-118). Cambridge, MA: MIT Press.) 


\section{Luke Glynn}

Suppes, P. (1970). A probabilistic theory of causality. Acta Philosophica Fennica 24. (Amsterdam: North-Holland Publishing Company)

Woodward, J. (2003). Making things happen: a theory of causal explanation. (New York: OUP)

Woodward, J. (2007). Causation with a human face. In Price and Corry (2007), 66-105.

Yablo, S. (2002). De facto dependence. Journal of Philosophy, 99, 130-148

Yablo, S. (2004). Advertisement for a sketch of an outline of a prototheory of causation. In Collins et al. (2004), 119-137. 